\title{
Does human bocavirus infection depend on helper viruses? A challenging case report
}

\author{
Monika Streiter ${ }^{1}$, Monika Malecki ${ }^{2}$, Aram Prokop', Verena Schildgen², Jessica Lüsebrink², Andreas Guggemos', \\ Matthias Wißkirchen ${ }^{1}$, Michael Weiß ${ }^{1}$, Reinhold Cremer ${ }^{1}$, Michael Brockmann ${ }^{2}$ and Oliver Schildgen ${ }^{2^{*}}$
}

\begin{abstract}
A case of severe diarrhoea associated with synergistic human bocavirus type 1 (HBoV) and human herpes virus type $6(H H V 6)$ is reported. The case supports the hypotheses that HBoV infection under clinical conditions may depend on helper viruses, or that HBoV replicates by a mechanism that is atypical for parvoviruses, or that HBoV infection can be specifically treated with cidofovir.
\end{abstract}

\section{Background}

The human bocavirus (HBoV) was discovered in 2005 by the Swedish group of Tobias Allander and colleagues [1]. By now, HBoV was detected in patients suffering from respiratory infections and gastrointestinal diseases, but a proof that $\mathrm{HBoV}$ is the causative agent in such cases is missing as it remains impossible so far to fulfil Koch's modified postulates [2]. The latter problem is caused by the fact that $\mathrm{HBoV}$ is hardly to propagate in cell culture [3] and that no transmission within an animal model was successful until today.

Since HBoV infections are accompanied by co-pathogens in a very high frequency it was postulated that $\mathrm{HBoV}$ is a passenger rather than a pathogen in airway infections [2], despite of the fact that $\mathrm{HBoV}$ causes a productive infection with viral shedding, viremia, and putatively persistence in different organs [4-7]. Although $\mathrm{HBoV}$ meanwhile was classified as an autonomous parvovirus [3] rather than a Dependovirus like the Adenoassociated virus (AAV) there remains the possibility that $\mathrm{HBoV}$ infections depend on helper viruses or at least contributes synergistically to the clinical course. Dependoviruses require a helper virus such as the polyomavirus SV40, herpes viruses, or adenoviruses, of which SV40 and Herpesviruses are known to be able to initiate a rolling circle genome replication [8-12]. A recent study has demonstrated that $\mathrm{HBoV}$ in turn is capable to

\footnotetext{
* Correspondence: schildgeno@kliniken-koeln.de

${ }^{2}$ Institut für Pathologie, Krankenhaus Merheim, Kliniken der Stadt Köln gGmbH, Klinikum der Privaten Universität Witten/Herdecke, Ostmerheimer Str.200, Cologne, 51109, Germany

Full list of author information is available at the end of the article
}

form head-to-tail DNA-sequences that on the other hand are a typical feature of a rolling circle replication. The presented case report provides evidence that the $\mathrm{HBoV}$ infection is probably dependent on herpesvirus replication or sensitive to anti-herpesviral therapy with the nucleotide analogue cidofovir.

\section{Case Report}

The patient is a 14 months old Caucasian male with a known history of a myelosarcoma with affected bone marrow, recurrent HHV6 pneumonia, and multiple hospitalisations for several reason. Of note, the patient also suffers from a secondary immunodeficiency with predominant global lack of Immunoglobulins A, G, and M, which origin is not yet determined.

In January 2011 the patient was hospitalized for severe pneumonia accompanied by Norovirus-induced gastroenteritis with severe diarrhoea. Thereby the hospitalisation was required as the symptoms of diarrhoea were recurring since November 2010 and resulted in a stop of weight gain with the risk of dehydration. The patient was released from the hospital 3 days later but was rehospitalized after four weeks due to aggravation of the gastrointestinal disease.

Despite reduced body weight the patient's general condition was classified as good, however accompanied by moderate anaemic but partially irritated flaked skin, reduced turgor, and wheezing, with radiological signs of an atypical pneumonia (banded shadows in the right upper lope and moderately reduced ventilation). Antibody levels and the blood lymphocyte count were extremely low, whilst monocytes and eosinophiles were 
significantly increased. Serologically, the patient was tested negative for CMV, EBV, parvovirus B19, and adenoviruses but positive for HHV6 with a viremia increasing from $5.3 \times 10^{6}$ to $7.8 \times 10^{6}$ copies per $\mathrm{ml}$ serum. Stool samples were tested negative for rotavirus, adenoviruses, norovirus, Clostridium difficile (strains and toxins), Salmonella, Shigella, Yersinia, and Campylobacter coli/jejuni as well as enteropathogenic E. coli.

Due to the ongoing and severe diarrhoea further analyses and pathological investigations were initiated. Thereby, the human herpes virus 6 (HHV6) infection was confirmed in blood, duodenum, and colon biopsies. Instead, human bocavirus was detected in stool and, surprisingly, in duodenum biopsies but not in blood or colon biopsies. Sequencing analyses and subsequent blastN revealed that $\mathrm{HBoV} 1$ was present with an Evalue of $5 \times 10^{-68}$ to $3 \times 10^{-65}$ and a total matching score ranging between 292 and 297. No further signs for a pathological disorder were detected. Based on the pathological and virological diagnoses antiviral therapy was started with Cidofovir. During this therapy, the HHV6 viremia decreased but remained detectable in both serum and stool samples taken in two intervals of 14 days; thereby, most surprisingly, during the Cidofovir therapy $\mathrm{HBoV}$ became undetectable in the stool samples 2 weeks after the onset of the antiviral therapy while HHV6 remained positive.

\section{Discussion}

In the recent past human bocavirus has been frequently associated with severe diarrhoea and turned out to be a most frequent agent in this clinical disorder [13-19], leading to the assumption that $\mathrm{HBoV}$ is the causative agent despite the missing proof of Koch's postulates for $\mathrm{HBoV}$ [2]. Thereby, mainly the genotypes 2-4 but not genotype 1 cause gastrointestinal infections, whilst the latter is mainly found in respiratory secretions. This latter observation is compatible with the fact that a mild respiratory infection with the clinical picture of a beginning atypical pneumonia was observed that was characterized by slight wheezing and radiological signs. The severe diarrhoea may have been a result of a synergistic interaction between the HHV6 infection and the superinfection by human bocavirus. Human herpes virus 6 was described to be a causative agent for prolonged diarrhoea in high risk patients [20]; the HHV6 associated diarrhoea may have been aggravated by the symptoms that are caused by human bocavirus. Although $\mathrm{HBoV}$ genotype 1 is mainly associated with respiratory infections it appears possible that in case of immuno-incompetent patients gastro-intestinal symptoms occur that are usually associated with the HBoV genotypes 2-4.

The case described here is interesting and surprising for two additional reasons: First, the presented case gives raise to the hypothesis that $\mathrm{HBoV}$ in fact replicates in the gastrointestinal tract, in particular in the duodenum as confirmed by positive PCR results from the clinical material of duodenum but a negative PCR for the colon samples. Thus, it appears likely that a locus for replication of human bocavirus was identified. Second, the observation that $\mathrm{HBoV}$ persisted until the onset of Cidofovir therapy is of major interest. On the one hand this observation leads to the hypothesis that $\mathrm{HBoV}$ itself is sensitive to Cidofovir and in turn we would have a specific drug available that could be administered in severe clinical cases. Cidofovir was described to display antiviral activity against DNA viruses beyond the family of herpesviruses [21,22]. On the other hand this observation could lead to a more groundbreaking hypothesis. Recently we have shown that in clinical samples DNA sequences were detectable that are of head-to-tail structure [23]. Head-to-tail sequences of viral genomes are a typical feature of a rolling circle replication [24] rather than of a rolling hairpin as postulated for other parvoviruses [25-27]. The hypothesis that $\mathrm{HBoV}$ may replicate in a classical rolling circle mechanism is supported by the fact that $\mathrm{HBoV}$ genomes are predominantly of negative sense polarity and that solely a minority of $\mathrm{HBoV}$ strains additionally encapsidates positive stranded progeny DNA [28]. Notably, rolling circle replication can be initiated by polyomaviruses and herpesviruses including HHV6 [29-34], both known to be able to act as helperviruses for the dependoviruses, a subfamily of parvoviruses that is not able to replicate autonomously [29-35]. The fact that in the presented case HHV6 accompanied the $\mathrm{HBoV}$ infection may consequently give raise to the hypothesis that $\mathrm{HBoV}$ in fact replicates in a rolling circle mechanism in the inner sense and that rolling circle replication of $\mathrm{HBoV}$ may be triggered by helperviruses. This assumption is supported by the fact that $\mathrm{HBoV}$ in the majority of clinical cases was described to be accompanied by at least one co-pathogen which in turn led to the ongoing discussion that $\mathrm{HBoV}$ is an innocent bystander rather than a true pathogen [36-41]. In concert with the observation that $\mathrm{HBoV}$ can replicate autonomously in primary cell culture [3] the present case report goes beyond and leads to the conclusion that $\mathrm{HBoV}$ infection can occur autonomously but can be triggered in its severity by co-infections that in turn may modify the molecular replication strategy of $\mathrm{HBoV}$. Although some of the hypotheses presented in this report remain a matter of speculation until it becomes possible to culture human bocavirus in a simplified culture system or in an animal model the presented observation are of major importance for the treatment of severe infections associated with $\mathrm{HBoV}$ and as thus deserve foremost attention. 


\section{Ethical Statement}

Written informed consent was obtained from the parents to publish the clinical case in anonymized form.

\section{Funding}

This study was supported by an unrestricted research grant from the Else Kröner-Fresenius Stiftung, Bad Homburg, Germany.

\author{
Author details \\ ${ }^{1}$ Klinik für Kinder- und Jugendmedizin, Kinderkrankenhaus, Kliniken der Stadt \\ Köln gGmbH, Amsterdamer Str. 59, Cologne, 50735, Germany. ${ }^{2}$ Institut für \\ Pathologie, Krankenhaus Merheim, Kliniken der Stadt Köln gGmbH, Klinikum \\ der Privaten Universität Witten/Herdecke, Ostmerheimer Str.200, Cologne, \\ 51109, Germany.
}

\section{Competing interests}

The authors declare that they have no competing interests.

Received: 2 August 2011 Accepted: 29 August 2011

Published: 29 August 2011

\section{References}

1. Allander T, Tammi MT, Eriksson M, Bjerkner A, Tiveljung-Lindell A, Andersson $\mathrm{B}$ : Cloning of a human parvovirus by molecular screening of respiratory tract samples. Proc Natl Acad Sci USA 2005, 102:12891-6.

2. Schildgen $\mathrm{O}$, Muller $\mathrm{A}$, Allander $\mathrm{T}$, et al: Human bocavirus: passenger or pathogen in acute respiratory tract infections? Clin Microbiol Rev 2008, 21:291-304, table of contents.

3. Dijkman R, Koekkoek SM, Molenkamp R, Schildgen O, van der Hoek L: Human bocavirus can be cultured in differentiated human airway epithelial cells. J Virol 2009, 83:7739-48.

4. Lu X, Gooding LR, Erdman DD: Human bocavirus in tonsillar lymphocytes. Emerg Infect Dis 2008, 14:1332-4.

5. Kuethe F, Lindner J, Matschke K, et al: Prevalence of parvovirus B19 and human bocavirus DNA in the heart of patients with no evidence of dilated cardiomyopathy or myocarditis. Clin Infect Dis 2009, 49:1660-6.

6. Kantola K, Hedman L, Allander T, et al: Serodiagnosis of human bocavirus infection. Clin Infect Dis 2008, 46:540-6.

7. Manning A, Willey SJ, Bell JE, Simmonds P: Comparison of tissue distribution, persistence, and molecular epidemiology of parvovirus B19 and novel human parvoviruses PARV4 and human bocavirus. J Infect Dis 2007, 195:1345-52.

8. Gerspach R, Matz B: Herpes simplex virus-induced "rolling circle" amplification of SV40 DNA sequences in a transformed hamster cell line correlates with tandem integration of the SV40 genome. Virology 1989, 173:723-7.

9. Gerspach R, Matz B: Herpes simplex virus-directed overreplication of chromosomal DNA physically linked to the simian virus 40 integration site of a transformed hamster cell line. Virology 1988, 165:282-5.

10. Dorsett D, Deichaite I, Winocour E: Circular and linear simian virus 40 DNAs differ in recombination. Mol Cell Biol 1985, 5:869-80.

11. Martin RG, Setlow VP: The initiation of SV40 DNA synthesis is not unique to the replication origin. Cell 1980, 20:381-91.

12. Sebring ED, Kelly TJ, Thoren MM, Salzman NP: Structure of replicating simian virus 40 deoxyribonucleic acid molecules. J Virol 1971, 8:478-90.

13. Kapoor A, Simmonds P, Slikas E, et al: Human bocaviruses are highly diverse, dispersed, recombination prone, and prevalent in enteric infections. J Infect Dis 2010, 201:1633-43.

14. Han TH, Kim CH, Park SH, Kim EJ, Chung JY, Hwang ES: Detection of human bocavirus-2 in children with acute gastroenteritis in South Korea. Arch Virol 2009, 154:1923-7.

15. von Linstow ML, Hogh M, Hogh B: Clinical and epidemiologic characteristics of human bocavirus in Danish infants: results from a prospective birth cohort study. Pediatr Infect Dis J 2008, 27:897-902.

16. Lau SK, Yip CC, Que TL, et al: Clinical and molecular epidemiology of human bocavirus in respiratory and fecal samples from children in Hong Kong. J Infect Dis 2007, 196:986-93.
17. Lee $J L$, Hung JY, Han TH, Song MO, Hwang ES: Detection of human bocavirus in children hospitalized because of acute gastroenteritis. $J$ Infect Dis 2007, 196:994-97.

18. Albuquerque MC, Rocha LN, Benati FJ, et al: Human bocavirus infection in children with gastroenteritis, Brazil. Emerg Infect Dis 2007, 13:1756-58.

19. Arthur JL, Higgins GD, Davidson GP, Givney RC, Ratcliff RM: A novel bocavirus associated with acute gastroenteritis in Australian children PLoS Pathog 2009, 5:e1000391.

20. Breddemann A, Läer S, Schmidt KG, et al: Case report: severe gastrointestinal inflammation and persistent HHV-6B infection in a paediatric cancer patient. Herpes 2007, 14:41-4.

21. Mayer TU, Marx A: Five molecules we would take to a remote island. Chem Biol 2010, 17:556-60.

22. De Clercq $\mathrm{E}$ : In search of a selective therapy of viral infections. Antiviral Res 2010, 85:19-24

23. Lüsebrink J, Schildgen V, Tillmann RL, et al: Detection of head-to-tail DNA sequences of human bocavirus in clinical samples. PLoS One 2011, accepted 30.03.2011.

24. Doermann AH: T4 and the rolling circle model of replication. Annu Rev Genet 1973, 7:325-41.

25. Cotmore SF, Tattersall P: An asymmetric nucleotide in the parvoviral $3^{\prime}$ hairpin directs segregation of a single active origin of DNA replication. Embo J 1994, 13:4145-52.

26. Tattersall $P$, Ward DC: Rolling hairpin model for replication of parvovirus and linear chromosomal DNA. Nature 1976, 263:106-9.

27. Tattersall P, Crawford LV, Shatkin AJ: Replication of the parvovirus MVM. II. Isolation and characterization of intermediates in the replication of the viral deoxyribonucleic acid. J Virol 1973, 12:1446-56.

28. Bohmer A, Schildgen V, Lusebrink J, et al: Novel application for isothermal nucleic acid sequence-based amplification (NASBA). J Virol Methods 2009, 158:199-201.

29. Alazard-Dany N, Nicolas A, Ploquin A, et al: Definition of herpes simplex virus type 1 helper activities for adeno-associated virus early replication events. PLoS Pathog 2009, 5:e1000340.

30. Geoffroy MC, Salvetti A: Helper functions required for wild type and recombinant adeno-associated virus growth. Curr Gene Ther 2005, 5:265-71.

31. Geoffroy MC, Epstein AL, Toublanc E, Moullier P, Salvetti A: Herpes simplex virus type 1 ICPO protein mediates activation of adeno-associated virus type 2 rep gene expression from a latent integrated form. J Virol 2004, 78:10977-86

32. Farkas SL, Zadori Z, Benko M, Essbauer S, Harrach B, Tijssen P: A parvovirus isolated from royal python (Python regius) is a member of the genus Dependovirus. J Gen Virol 2004, 85:555-61.

33. Thomson BJ, Weindler FW, Gray D, Schwaab V, Heilbronn R: Human herpesvirus 6 (HHV-6) is a helper virus for adeno-associated virus type 2 (AAV-2) and the AAV-2 rep gene homologue in HHV-6 can mediate AAV2 DNA replication and regulate gene expression. Virology 1994, 204:304-11.

34. Fisher RE, Mayor HD: The evolution of defective and autonomous parvoviruses. J Theor Biol 1991, 149:429-39.

35. Berns Kl: Parvovirus replication. Microbiol Rev 1990, 54:316-29.

36. Weissbrich B, Neske F, Schubert J, et al: Frequent detection of bocavirus DNA in German children with respiratory tract infections. BMC Infect Dis 2006, 6:109.

37. Chow BD, Esper FP: The human bocaviruses: a review and discussion of their role in infection. Clin Lab Med 2009, 29:695-713.

38. Tan BH, Lim EA, Seah SG, et al: The incidence of human bocavirus infection among children admitted to hospital in Singapore. J Med Virol 2009, 81:82-9.

39. Zhang $L L$, Tang $L Y, X i e Z D$, et al: Human bocavirus in children suffering from acute lower respiratory tract infection in Beijing Children's Hospital. Chin Med J (Engl) 2008, 121:1607-10.

40. Garcia ML, Calvo C, Pozo F, Perez-Brena P, Vazquez MC, Casas I: Detection of human bocavirus in ill and healthy Spanish children: a 2-year study. Arch Dis Child 2009.

41. Bonzel L, Tenenbaum T, Schroten $H$, Schildgen O, Schweitzer-Krantz S, Adams O: Frequent detection of viral coinfection in children hospitalized with acute respiratory tract infection using a real-time polymerase chain reaction. Pediatr Infect Dis J 2008, 27:589-94.

doi:10.1186/1743-422X-8-417

Cite this article as: Streiter et al:: Does human bocavirus infection depend on helper viruses? A challenging case report. Virology Journal $20118: 417$ 